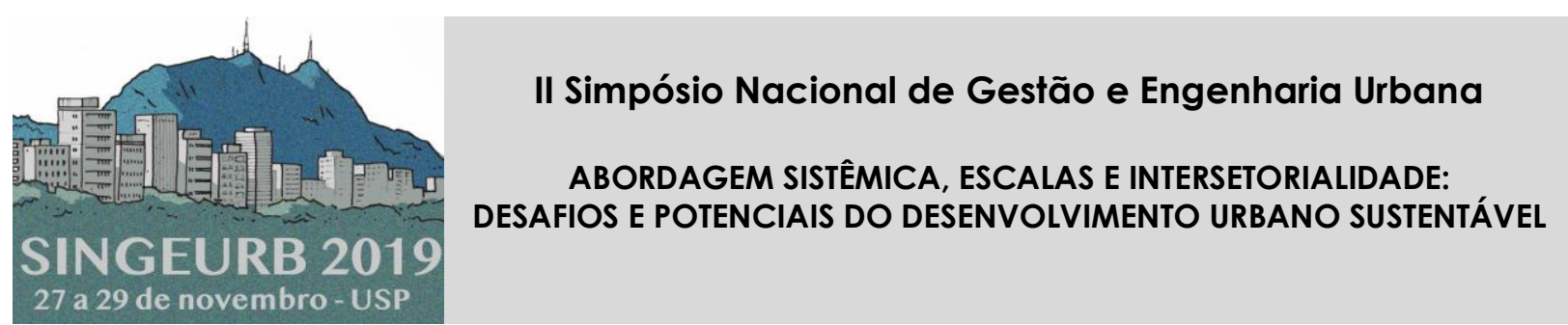

\title{
Estudo da viabilidade econômica para sistema de aproveitamento de águas de chuva na sede da companhia brasileira de trens urbanos em João Pessoa/PB 1
}

\section{Economic viability study of rainwater harvesting system at the Brazilian urban train company head office in João Pessoa/PB}

\author{
Afonso Eris Ferreira de Andrade 1; Gilson Barbosa Athayde Júnior 2; Mariko de \\ Almeida Carneiro ${ }^{3}$; Elda Karoline Videres Ferraz 4 \\ 1 Universidade Federal da Paraíba, Brasil, afonsoeris@hotmail.com \\ 2 Universidade Federal da Paraíba, gilson@ct.ufpb.br \\ ${ }^{3}$ Companhia Brasileira de Trens Urbanos, mariko.carneiro@gmail.com \\ 4 Universidade Federal da Paraíba, eldakaroline@gmail.com
}

\begin{abstract}
RESUMO
O objetivo deste estudo é analisar economicamente a implantação de um sistema de aproveitamento de água de chuva na sede da Companhia Brasileira de Trens Urbanos em João Pessoa. A avaliação consiste em examinar a utilização da água pluvial para três usos não-potáveis: lavagem de trens, jardinagem e descarga em bacias sanitárias. O sistema de aproveitamento pluvial é analisado em função do volume de armazenamento e também em dois cenários de consumo: no primeiro, a água seria utilizada para jardinagem e lavagem de trens; enquanto, no outro cenário, considerar-se-ia adicionalmente o consumo das descargas. A análise financeira é realizada através dos indicadores econômicos: valor presente líquido, tempo de retorno de capital descontado e relação benefício-custo ao longo dos 25 anos de vida útil do projeto, aplicando-se uma taxa de juros de 11,53\% ao ano. O diagnóstico de viabilidade econômica do primeiro cenário identifica que os reservatórios inferiores a $11 \mathrm{~m}^{3}$ são inviáveis economicamente. Por outro lado, no mesmo cenário os reservatórios com volumes superiores a $11 \mathrm{~m}^{3}$ apresentam indicadores econômicos satisfatórios, apontando a viabilidade do sistema. Quando acrescida a água para descargas em bacias sanitárias no consumo, o sistema de aproveitamento mostra-se viável para todos os volumes de reservatórios analisados.
\end{abstract}

Palavras-chave: reuso da água, aproveitamento de água pluvial, viabilidade econômica.

\begin{abstract}
The objective of this study is to analyze the implementation of a rainwater harvesting system at the headquarters of Companhia Brasileira de Trens Urbanos in João Pessoa. The evaluation consists in using rainwater in three non-potable applications: train washing, gardening and discharges of sanitary basins. The rainwater harvesting system is studied according to the

\footnotetext{
${ }^{1}$ ANDRADE, Afonso Eris Ferreira de; ATHAYDE JUNIOR, Gilson Barbosa; CARNEIRO, Mariko de Almeida; FERRAZ, Elda Karoline Videres. Estudo da viabilidade econômica para sistema de aproveitamento de águas de chuva na sede da Companhia Brasileira de Trens Urbanos em João Pessoa/PB. In: II SIMPÓSIO NACIONAL DE GESTÃO E ENGENHARIA URBANA: SINGEURB, 2019, São Paulo. Anais... Porto Alegre: ANTAC, 2019.
} 
storage volume and in two consumption scenarios: in the first, water is used for gardening and washing of trains; while in the other scenario the consumption of discharges is considered additionally. The financial analysis consists of three economic indicators: net present value, discounted payback and benefit-cost ratio, over the 25-year life of the project, applying an average interest rate of $11.53 \%$ per year. The economic viability diagnostic of the first scenario identifies that the reservoirs below $11 \mathrm{~m}^{3}$ are not economically viable. On the other hand, in the same scenario, the reservoirs with volumes greater than $11 \mathrm{~m}^{3}$ presents satisfactory economic indicators suggesting the feasibility of the system. When water from discharges from sanitary basins is added to the consumption, the rainwater reuse system is feasible in all the volumes of reservoirs studied.

Keywords: water reuse, rainwater harvesting, economic viability.

\section{INTRODUÇÃO}

A Superintendência de Trens Urbanos de João Pessoa (STU-JOP), subsidiária da Companhia Brasileira de Trens Urbanos (CBTU), em 2017, implementou o Programa de Consumo Sustentável de Água e Energia (CAES) com objetivo de promover o uso sustentável de água e energia elétrica. O programa foi elaborado segundo a Agenda Ambiental da Administração Pública (A3P) que busca estimular ações ambientais e propagar os princípios da responsabilidade socioambiental. A mudança de atitude dos servidores públicos, a redução do desperdício dos recursos naturais, a substituição das tecnologias ineficientes e a adoção de fontes alternativas de água e energia são os objetivos essenciais do CAES (CBTU, 2018).

Uma das principais ações do programa em 2018 compreendia a análise da viabilidade de soluções sustentáveis para abastecimento de água e energia. Desse modo, desenvolveu-se uma análise técnico-financeira, enquadrada no plano de ações, referente a implantação de um sistema de aproveitamento de água de chuva na sede da CBTU quantificando seus benefícios e custos para usos não-potáveis como: a descarga em bacias sanitárias, a irrigação de jardins e a lavagem de trens.

\section{REFERENCIAL TEÓRICO}

O aproveitamento de águas de chuva surge como uma alternativa sustentável para o uso de água em edificações, diminuindo o uso da água potável. Além disso, é considerado uma opção que pode ser integrada aos sistemas convencionais de abastecimento permitindo o gerenciamento eficaz da água, e igualmente evitando a degradação dos recursos hídricos (ATSE, 2004).

A captação e o reuso da água de chuva representam um rompimento da centralidade dos sistemas de abastecimento público e minimizam a vulnerabilidade dos grandes centros urbanos: garante ainda uma maior resiliência urbana à água, pois diminui a demanda por água tratada, minimiza os picos de vazão de chuvas no sistema de drenagem urbana, podendo amenizar as enchentes, e reduz a compra de água potável (Marinho, 2018; Tomaz, 2010).

É imprescindível analisar sob todos os aspectos os benefícios do aproveitamento de água de chuva. Entretanto, as implicações técnicas, sociais ou ambientais da implantação de um projeto não são verificadas no estudo econômico, o qual analisa simplesmente os valores numéricos que subsidiam a decisão de execução e viabilidade da proposta.

Dias (2007), Marques (2012), Pozzebon (2016) e Martins (2017) utilizam os indicadores econômicos: valor presente líquido, relação benefício-custo e tempo de retorno de capital, para analisar a viabilidade econômica de sistemas de aproveitamento predial de água de chuva.

O valor presente líquido (VPL) determina a diferença entre todos os benefícios e custos envolvidos ao longo do horizonte de projeto e transforma-os em valores presentes. Esse indicador calcula o saldo entre o valor de benefícios líquidos de caixa e o valor presente dos 
investimentos em cada período de duração do projeto considerando uma taxa específica que desconta os fluxos de caixa no decorrer do projeto (ASSAF NETO \& LIMA, 2011).

Do mesmo modo, o tempo de retorno de capital (TRC) descontado é o tempo necessário para que o retorno econômico de um investimento supere seus custos considerando a taxa de desconto do capital ou a depreciação das riquezas monetárias (GOMES, 2005).

A relação benefício-custo $(B / C)$, também denominada de índice de lucratividade, é calculada pelo quociente do valor presente líquido e o desembolso de capital e representa o quanto de valor econômico é criado por unidade monetária investida (ASSAF NETO \& LIMA, $2011)$.

\section{METODOLOGIA}

O local da realização da pesquisa é a sede da Companhia Brasileira de Trens Urbanos em João Pessoa/PB, no bairro do Varadouro, onde funciona a estação mais movimentada do sistema de trens urbanos da capital.

Para o estudo, extraíram-se os dados pluviométricos do Sistema Nacional de Informações sobre Recursos Hídricos (SNRIH) da Agência Nacional de Águas (ANA) no portal Hidroweb da estação pluviométrica mais próxima do local de estudo. O cálculo do regime mensal médio de chuvas foi realizado pelos dados pluviométricos dos últimos 34 anos de operação da estação pluviométrica: de janeiro de 1983 até dezembro de 2016. O gráfico 1 apresenta os dados de precipitação anuais ao longo de toda séria histórica e o gráfico 2, as precipitações médias mensais.

Gráfico 1 - Série Histórica de chuvas anuais do posto pluviométrico entre 1983 e 2016

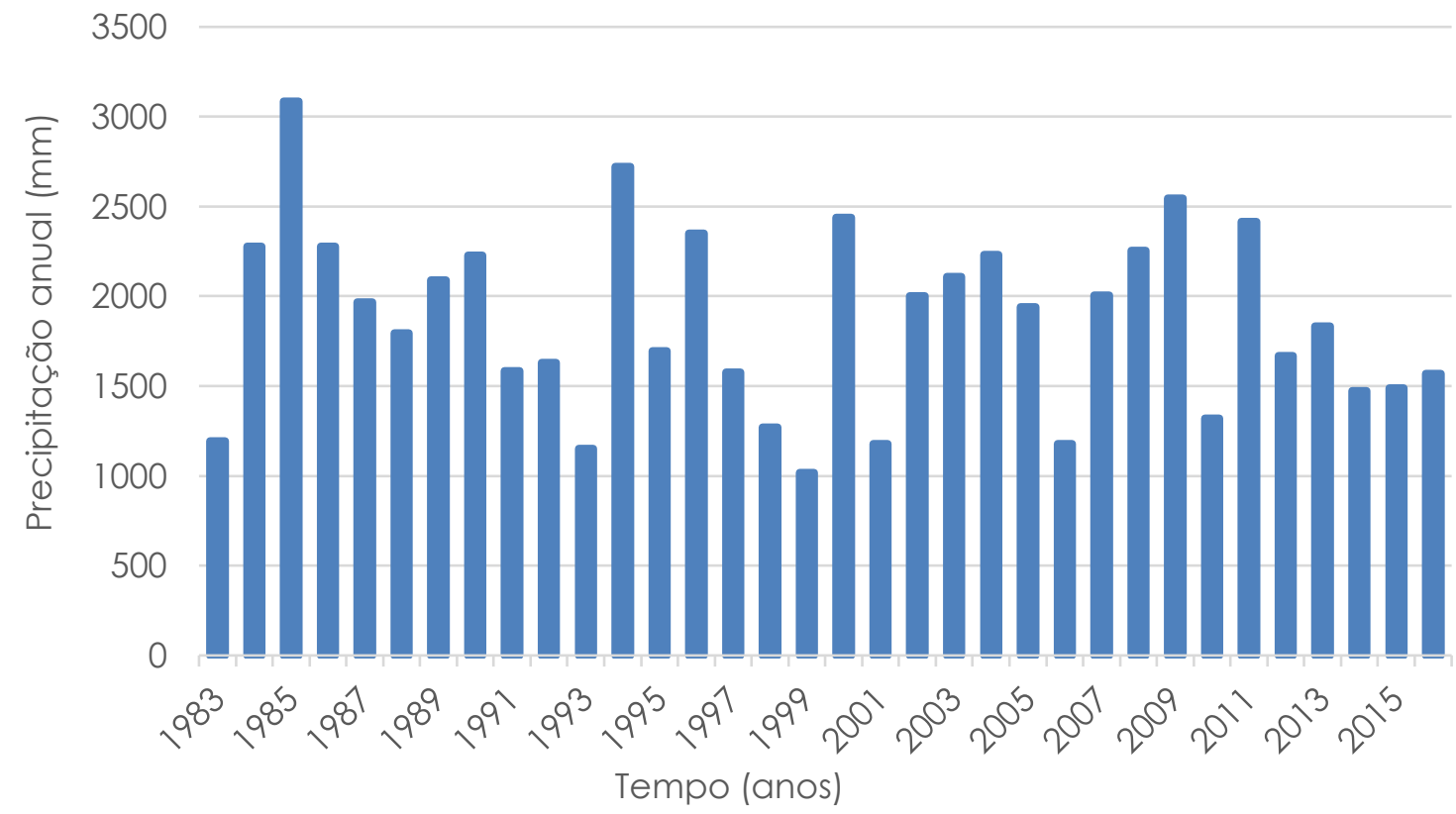

Fonte: ANA, 2018 


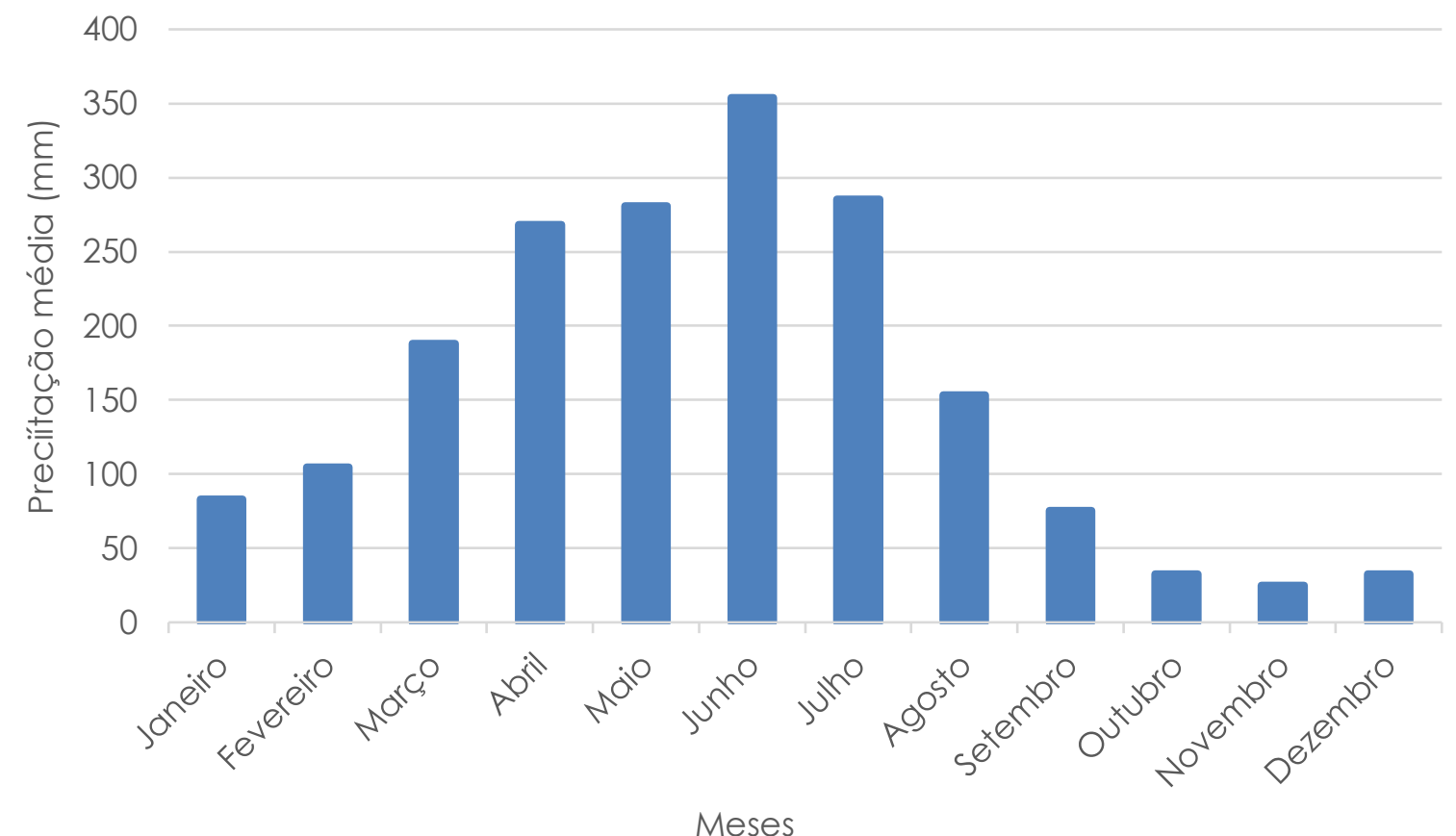

Fonte: ANA, 2008

A coleta de água de chuva é realizada pelas cobertas de telhas cerâmicas e metálicas dos prédios existentes, e o sistema idealizado é composto por tubulações de PVC, caixas de inspeção em concreto pré-moldado, reservatório inferior em polietileno simplesmente apoiado, filtro de areia com base em concreto armado, bomba para recalque e reservatório superior de polietileno de 1000L.

Realizou-se o levantamento de área de coberta disponível para captação de água pluvial e aplicou-se o coeficiente de Runoff de 0.90 para a obtenção dos dados volumétricos de entrada no sistema de captação e armazenamento. Igualmente, identificou-se os volumes de água das atividades realizadas que poderiam ser executadas com água de qualidade inferior.

O consumo de jardinagem foi estimado através de uma taxa de aplicação diária média, sugerida por Tomaz (2010) de $2 \mathrm{~L} / \mathrm{m}^{2}$.dia, apenas nos meses de chuva abaixo da média mensal, de Setembro a Fevereiro. O volume consumido pelas descargas de bacias sanitárias foi medido considerando a quantidade de empregados, de desembarques de trens na estação, de descargas por desembarque e por funcionário. Por último, o volume médio de água gasto na lavagem dos trens foi medido in loco em conjunto com a equipe de limpeza nos dias de higienização dos veículos.

Além disso, a implantação do sistema é analisada em dois cenários diferentes de consumo e com reservatórios de polietileno em diversas situações de armazenamento: $3 \mathrm{~m}^{3}, 5 \mathrm{~m}^{3}, 10 \mathrm{~m}^{3}$, $15 \mathrm{~m}^{3}, 20 \mathrm{~m}^{3}, 40 \mathrm{~m}^{3}, 60 \mathrm{~m}^{3}, 80 \mathrm{~m}^{3}, 100 \mathrm{~m}^{3}, 120 \mathrm{~m}^{3}$ e $140 \mathrm{~m}^{3}$. Neste sentido, o cenário 01 compreende apenas os consumos de jardinagem e lavagem de trens, enquanto no cenário 02 consta jardinagem, lavagem de trens e descargas de bacias sanitárias. Então, o balanço volumétrico do sistema de armazenamento foi determinado através da oferta de água de chuva, das demandas para uso não-potável e do volume de armazenamento, a fim de determinar o volume aproveitado de água pluvial por ano. Identificou-se os custos de investimento diretos e indiretos, de exploração, e os benefícios econômicos vinculados. Os valores dos custos de investimento são fornecidos pelo catálogo de composições não desoneradas do SINAPI/PB de julho de 2018 da Caixa Econômica Federal. Estimou-se um gasto de manutenção de R\$ 1.000,00 por ano, conforme Martins (2017), necessários para limpeza das cobertas e calhas, manutenção da bomba, desobstrução de tubos e desinfecção dos tanques. Ademais, a 
tarifa média de energia elétrica, utilizada para bombeamento, custa 0,76219 R $\$ / \mathrm{KWh}$ e a tarifa de água para o serviço público é de 12,89 R $\$ / \mathrm{m}^{3}$. Por fim, considerou-se um horizonte de projeto de 25 anos com taxa de juros igual a $11,53 \%$ ao ano correspondente a uma média ponderada temporal da taxa Selic de janeiro de 2015 a junho de 2018 . A figura 1 ilustra os passos da pesquisa e o gráfico 2 mostra o crescimento do investimento total segundo 0 volume do reservatório.

Figura 1 - Diagrama metodológico

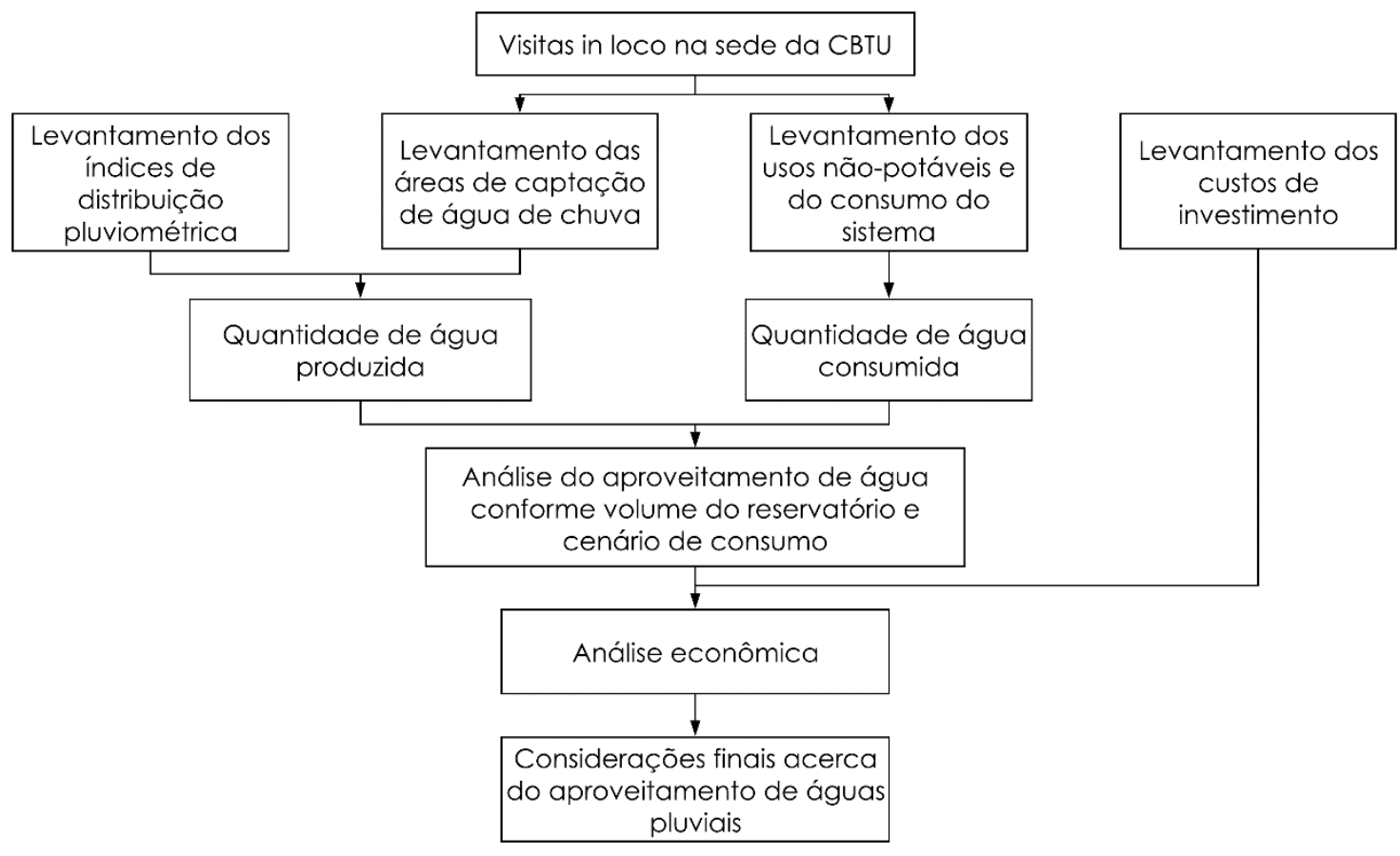

Fonte: Os autores

Gráfico 2 - Investimento inicial pelo volume de armazenamento

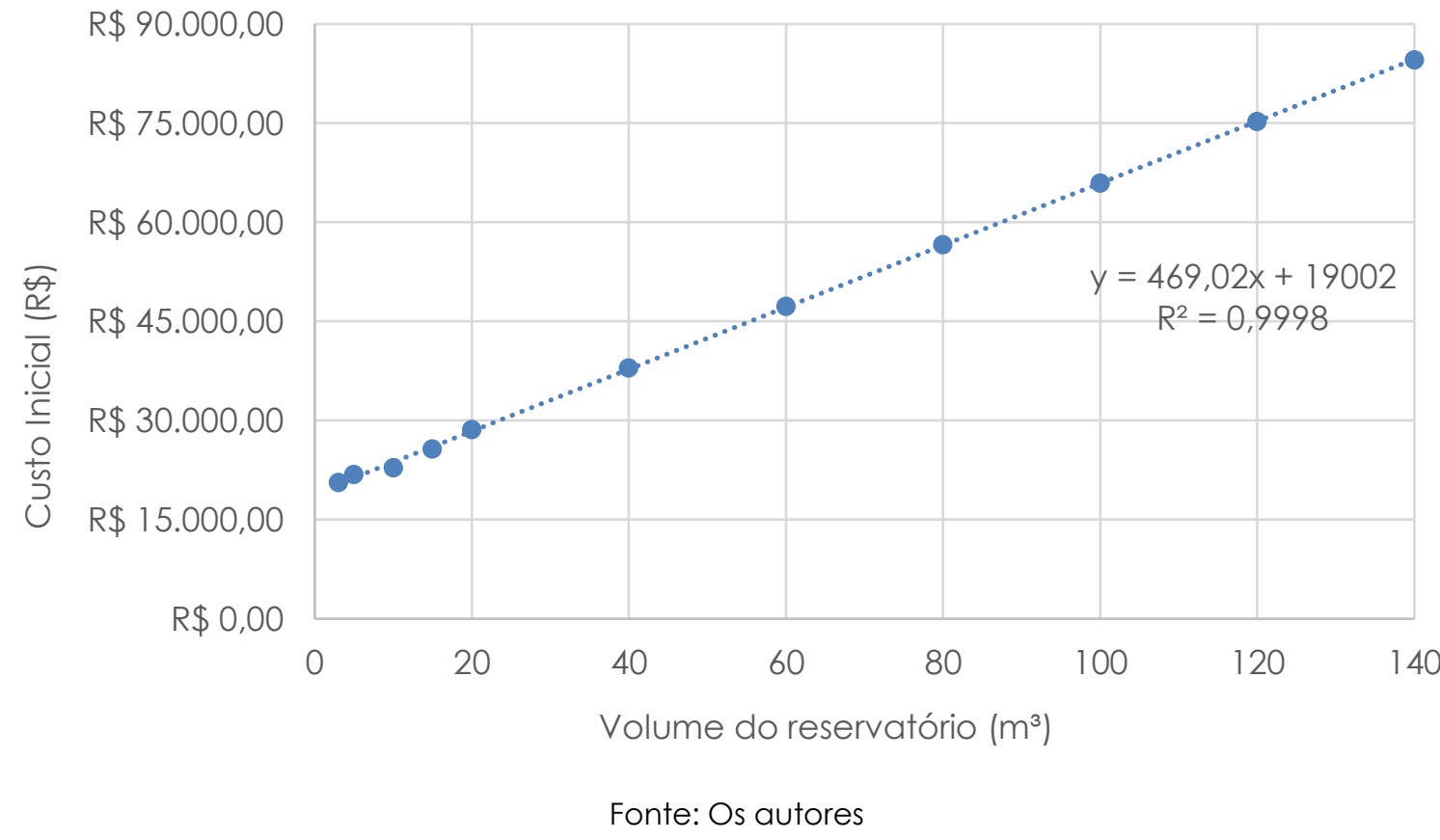




\section{RESULTADOS}

O sistema de aproveitamento de água pluvial é proposto com área de captação de 1250 $\mathrm{m}^{2}$, numa localidade com pluviometria média de $156 \mathrm{~mm}$ por mês, resultando num fornecimento de água não-potável de $28 \mathrm{~m}^{3}$ a $398 \mathrm{~m}^{3}$ por mês. A análise econômica é realizada para reservatórios de diversos tamanhos com volume de armazenamento com resultados apresentados na tabela 1 e nos gráficos $3,4,5$ e 6 .

Tabela 1 - Indicadores técnicos e econômicos segundo o volume do reservatório

\begin{tabular}{|c|c|c|c|c|c|c|c|c|}
\hline \multirow{2}{*}{$\begin{array}{l}\text { Volume do } \\
\text { Reservatório } \\
\left(\mathrm{m}^{3}\right)\end{array}$} & \multicolumn{2}{|c|}{$\begin{array}{c}\text { Volume } \\
\text { aproveitado }\left(\mathrm{m}^{3}\right)\end{array}$} & \multicolumn{2}{|c|}{ VPL (R\$) } & \multicolumn{2}{|c|}{ TRC (anos) } & \multicolumn{2}{|c|}{$\mathrm{B} / \mathrm{C}$} \\
\hline & $\begin{array}{c}\text { Cenário } \\
1\end{array}$ & $\begin{array}{c}\text { Cenário } \\
2\end{array}$ & $\begin{array}{c}\text { Cenário } \\
1\end{array}$ & $\begin{array}{c}\text { Cenário } \\
2\end{array}$ & $\begin{array}{c}\text { Cenário } \\
1\end{array}$ & $\begin{array}{c}\text { Cenário } \\
2\end{array}$ & $\begin{array}{c}\text { Cenário } \\
1\end{array}$ & $\begin{array}{c}\text { Cenário } \\
2\end{array}$ \\
\hline 3 & 176,24 & 669,54 & $-9151,56$ & 48218,91 & - & 3,01 & 0,56 & 3,34 \\
\hline 5 & 200,24 & 687,54 & $-7572,90$ & 49099,77 & - & 3,09 & 0,65 & 3,25 \\
\hline 10 & 258,99 & 732,54 & $-1750,76$ & 53322,80 & - & 3,01 & 0,92 & 3,34 \\
\hline 15 & 313,99 & 777,00 & 1773,65 & 55621,65 & 19,70 & 3,17 & 1,07 & 3,16 \\
\hline 20 & 363,54 & 817,00 & 4614,54 & 57351,77 & 14,99 & 3,52 & 1,16 & 3,00 \\
\hline 40 & 543,54 & 959,88 & 16223,88 & 64644,21 & 9,85 & 3,91 & 1,43 & 2,70 \\
\hline 60 & 723,54 & 1087,43 & 27833,22 & 70153,24 & 8,46 & 4,25 & 1,59 & 2,48 \\
\hline 80 & 882,88 & 1207,43 & 37040,17 & 74784,64 & 7,76 & 4,79 & 1,65 & 2,32 \\
\hline 100 & 1021,43 & 1327,43 & 43828,49 & 79416,03 & 7,71 & 5,04 & 1,66 & 2,20 \\
\hline 120 & 1141,43 & 1445,33 & 48459,89 & 83802,72 & 7,81 & 5,26 & 1,64 & 2,11 \\
\hline 140 & 1261,43 & 1545,33 & 53091,28 & 86108,14 & 7,88 & 5,78 & 1,63 & 2,02 \\
\hline
\end{tabular}

Gráfico 3 - Volume anual aproveitado pelo volume de armazenamento

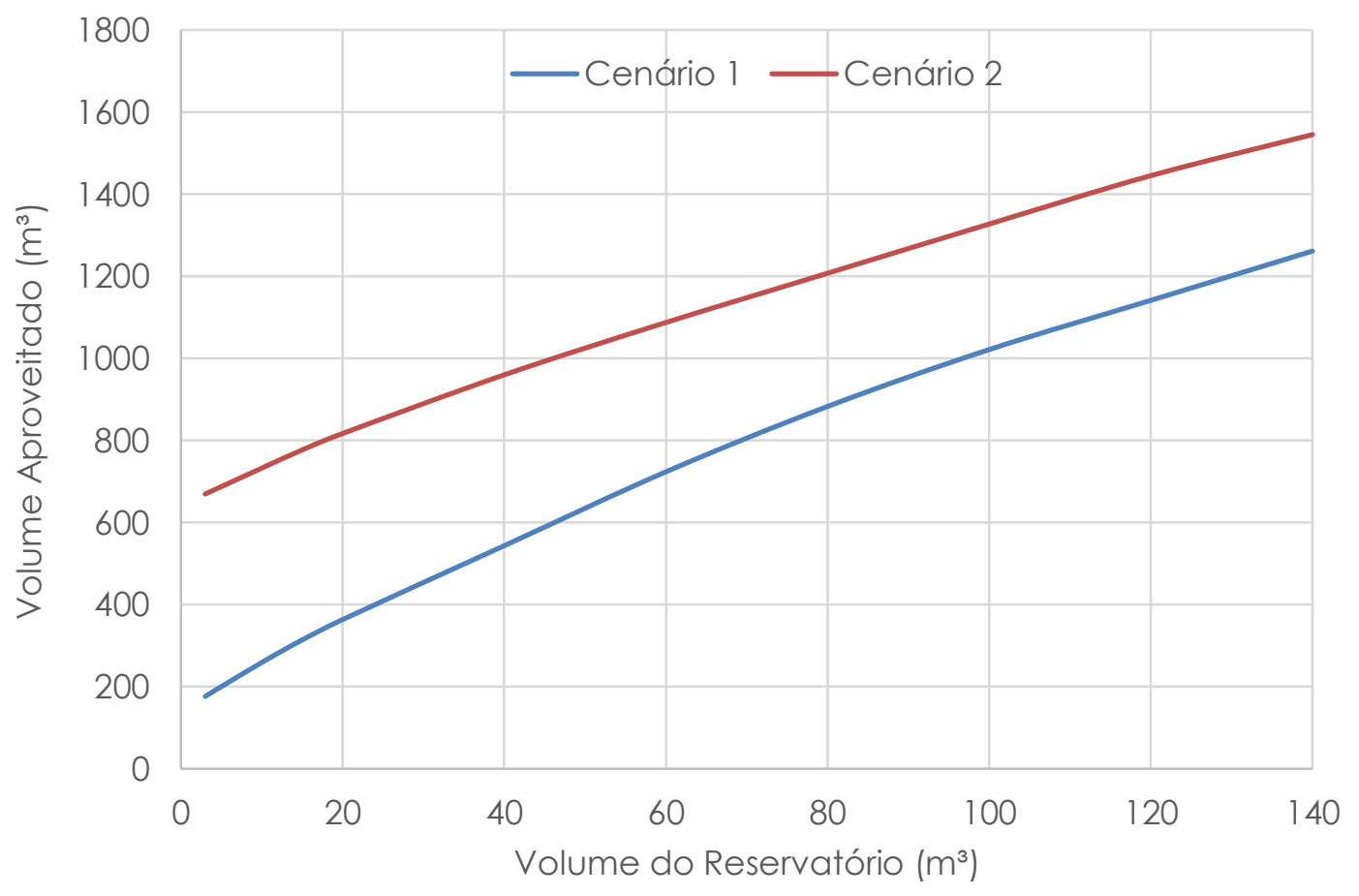

Fonte: Os autores 
Gráfico 4 - Valor presente líquido pelo volume de armazenamento

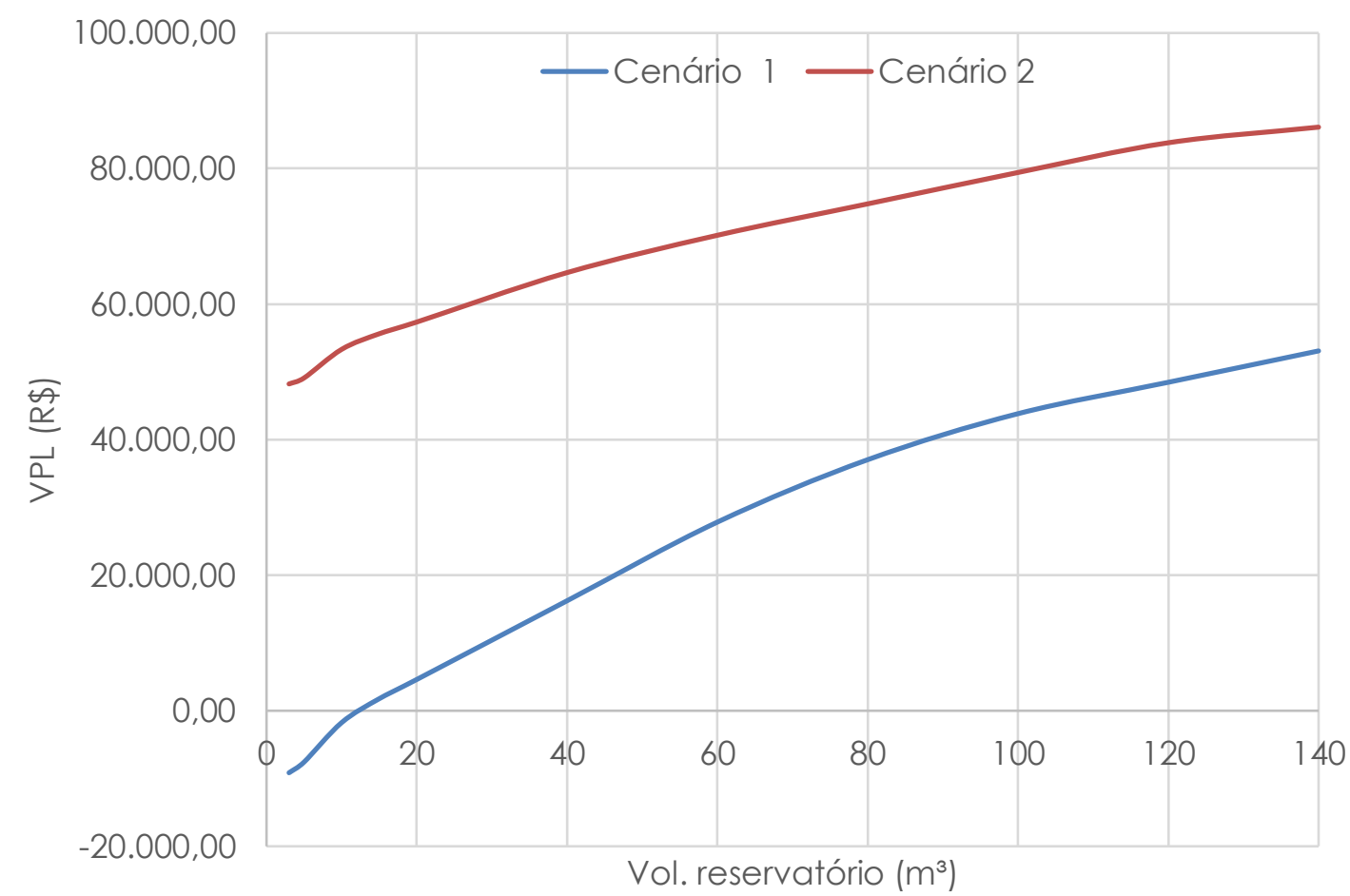

Fonte: Os autores

Gráfico 5 - Tempo de retorno de capital pelo volume de armazenamento

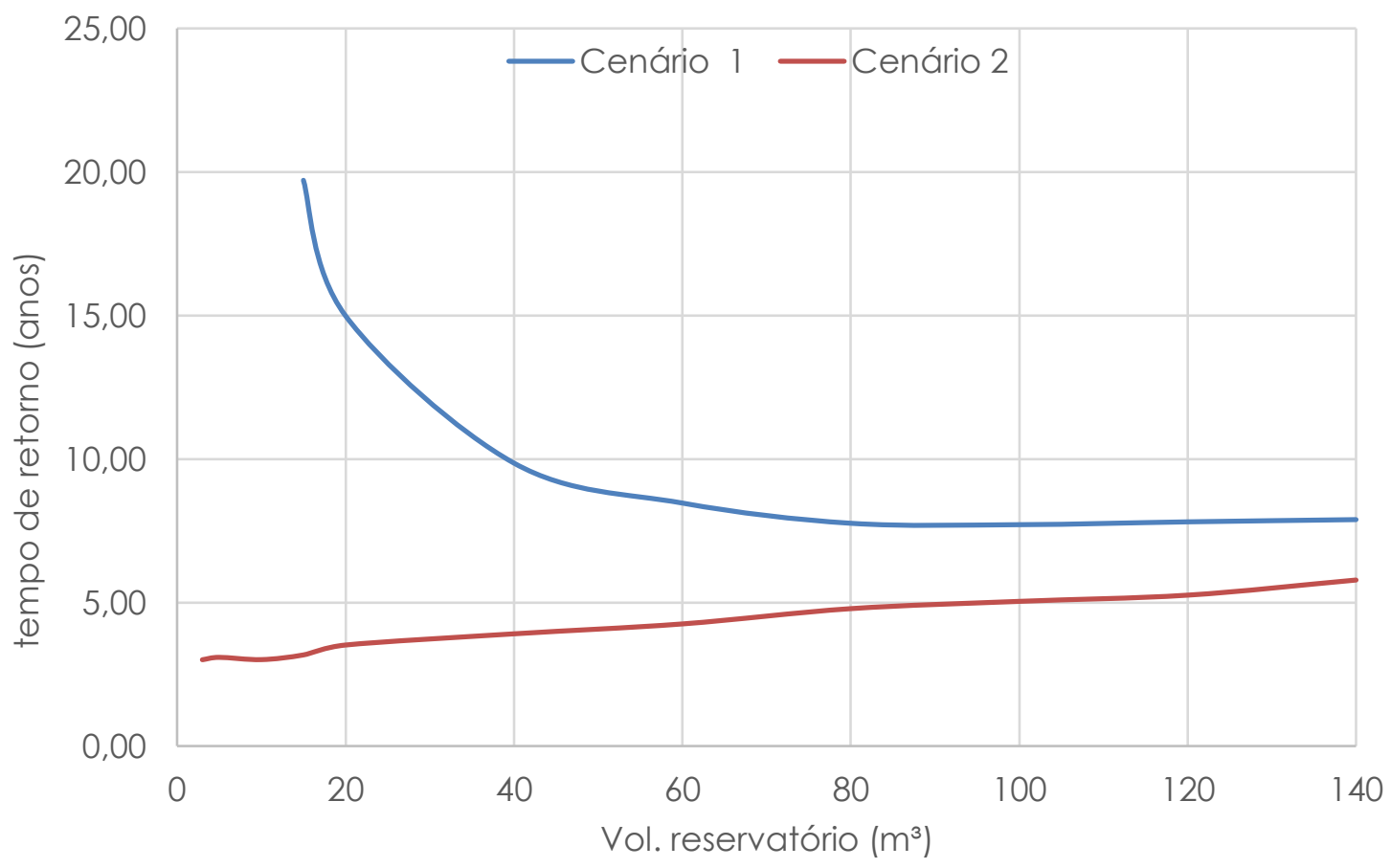

Fonte: Os autores 
Gráfico 6 - Relação benefício-custo pelo volume de armazenamento

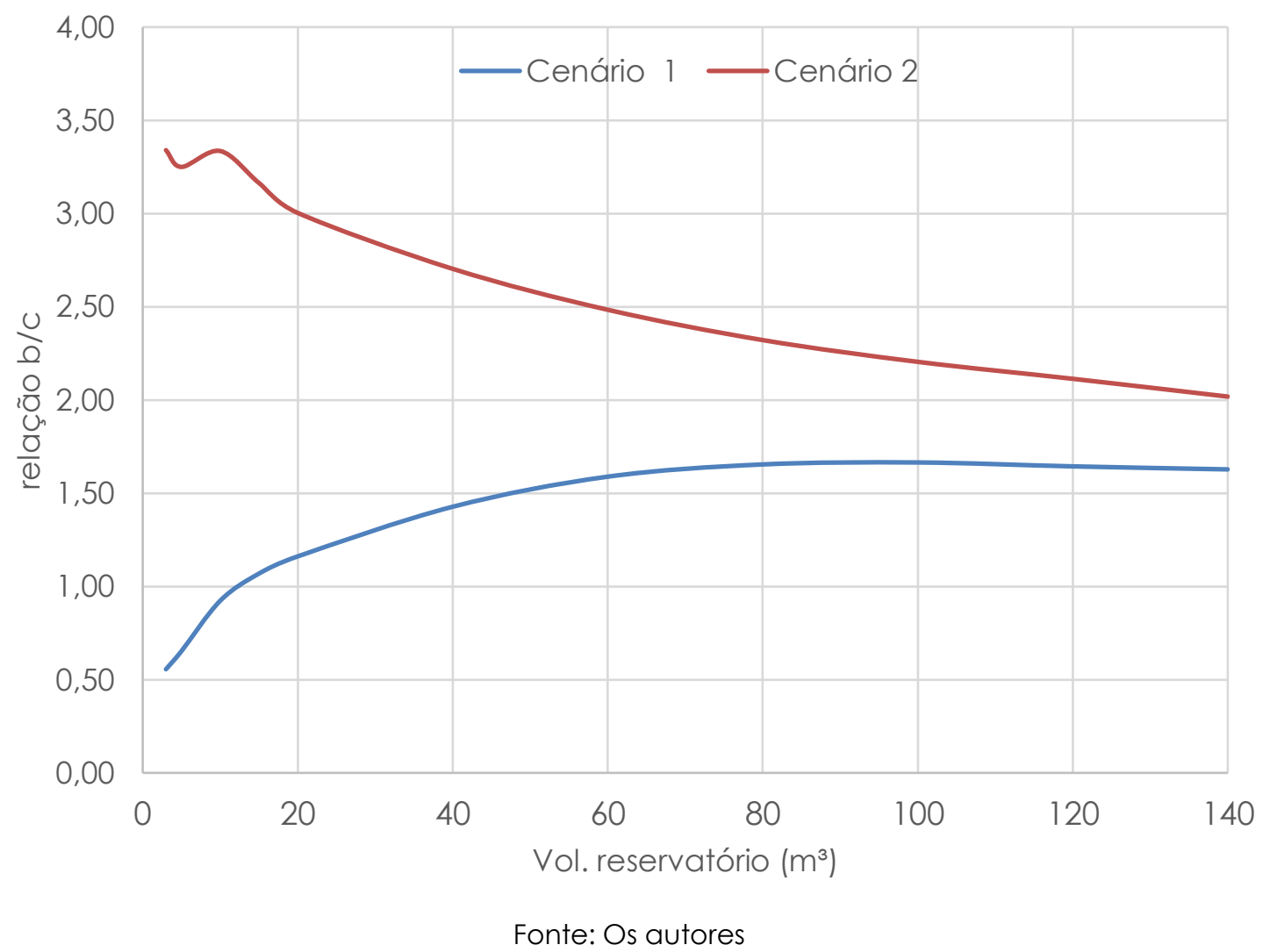

O sistema de aproveitamento de água de chuva apresentou volumes de aproveitamento, variando entre $200 \mathrm{~m}^{3}$ a $1500 \mathrm{~m}^{3}$ por ano independentemente do cenário, que são suficientes para garantir a sua funcionalidade e aceitação técnica.

Com relação à análise econômica do sistema, os resultados do VPL apontam que no cenário 1 qualquer sistema com armazenamento superior a $11 \mathrm{~m}^{3}$ é suficiente para garantir um retorno financeiro ao longo da vida útil de projeto. Enquanto, no cenário 2 qualquer reservatório possui VPL positivo até o fim do horizonte de projeto. Quanto ao tempo de retorno de capital no cenário 1, o TRC reduz com o aumento de volume do reservatório e estabiliza a partir dos $100 \mathrm{~m}^{3}$ tendendo a atingir um valor em torno de 8 anos, por outro lado, no cenário 2, o TRC aumenta em pequenas proporções, à medida que o volume do reservatório cresce. Por fim, a relação benefício-custo no cenário de menor consumo cresce até os $100 \mathrm{~m}^{3}$ e tende a estabilizar em torno de 1,60. Quando considerado o aumento do consumo pelas descargas, a relação decresce com aumento do volume e tende a 2,00. Nota-se que, nesse estudo, os indicadores econômicos são bastante susceptíveis à variação do consumo. Por exemplo, no cenário 1, devido à sensibilidade do sistema ao consumo, uma pequena adição à demanda pode representar a viabilidade de um sistema de baixo investimento inicial.

\section{CONCLUSÃO}

Em síntese, o cenário de menor consumo apresenta inviabilidade de implantação do sistema de aproveitamento de água de chuva nos reservatórios menores que $11 \mathrm{~m}^{3}$, pelo fato do custo de implantação ser muito superior aos benefícios providos. Entretanto, o aumento do consumo transformou as soluções com baixo volume de armazenamento, que apresentam tempo de retorno inexistente e menor relação benefício-custo, nas soluções de menor tempo de retorno e maior relação benefício-custo.

Conclui-se que a implantação de um sistema de aproveitamento de água de chuva é atraente e viável em termos técnicos e econômicos. Assim, o reuso da água de chuva deve 
ser subsidiado, em consequência de suas numerosas vantagens e baixas possibilidades de prejuízo financeiro, como forma de promover $\mathrm{o}$ debate de políticas públicas e desenvolvimento sustentável.

\section{AGRADECIMENTOS}

Agradecemos à Companhia Brasileira de Trens Urbanos pela colaboração e apoio, que foram essenciais ao desenvolvimento do estudo.

\section{REFERÊNCIAS}

ANA - AGÊNCIA NACIONAL DE ÁGUAS. HidroWeb: sistemas de informações hidrológicas. Disponível em: <http://hidroweb.ana.gov.br/HidroWeb>. Acesso em agosto de 2018.

ASSAF NETO, A.; LIMA, F. G. Curso de administração financeira. São Paulo: Atlas, 2011.

ATSE. Water Recycling in Australia: A review undertaken by the Australian Academy of Technological Sciences and Engineering. Australian Academy of Technological Sciences and Engineering. Victoria, 2004. Disponível em:

<https://www.atse.org.au/Documents/reports/water-recycling-in-australia.pdf $>$. Acesso em: 20 ago. 2018.

CBTU, Companhia Brasileira de Trens Urbanos. Programa de Consumo de Água e Energia Sustentável: Relatório Final 2017. João Pessoa, março de 2018.

DIAS, I. C. S. Estudo da viabilidade técnica, econômica e social do aproveitamento de água de chuva em residências na cidade de João Pessoa. Dissertação de Mestrado. Universidade Federal da Paraíba. João Pessoa, 2007.

GOMES, H. P. Eficiência hidráulica e energética em saneamento: Análise econômica de projetos. Rio de Janeiro: ABES. ISBN: 85-7022-47-9. 114 p, 2005.

MARINHO, S. D. A. M. Planejamento urbano sensível aos recursos hídricos: análise a partir do metabolismo urbano e da população do espaço em Campina Grande-PB - Universidade Federal de Campina Grande, 2018. Disponível em: <http://dspace.sti.ufcg.edu.br:8080/jspui/handle/riufcg/388>. Acesso em: 03 out. 2018.

MARQUES, C. M. Proposição de sistema de aproveitamento de água de chuva para o campus Campina Grande do IFPB: Estudo de viabilidade econômica. Dissertação de Mestrado. Universidade Federal da Paraíba. João Pessoa, 2012.

MARTINS, R. T. Estudo da viabilidade econômica para uso de águas pluviais no hospital metropolitano de Santa Rita. Trabalho de conclusão de curso - Universidade Federal da Paraíba. João Pessoa, 2017.

POZZEBON, P. H. B. Viabilidade técnica, econômica e social do aproveitamento das águas de chuva e cinzas para consumo não potável na cidade de Santa Maria/RS. Dissertação de Mestrado - Universidade Federal de Santa Maria. Santa Maria, 2016.

TOMAZ, P. Aproveitamento de água de chuva em áreas urbanas para fins não potáveis. Guarulhos, 2010. Disponível em:

<http://www.pliniotomaz.com.br/downloads/livros/Livro_aprov._aguadechuva/Livro\%20Apro veitamento\%20de\%20agua\%20de\%20chuva\%205\%20dez\%202015.pdf> Acesso em: 28 set. 2018. 